\title{
A Sorption Study of Bisphenol A in Aqueous Solutions on Pristine and Oxidized Multi-Walled Carbon Nanotubes
}

\author{
Raluca Madalina Senin ${ }^{1,2}$, Ion Ion², Alina Catrinel Ion ${ }^{2 *}$ \\ ${ }^{1}$ National Research and Development Institute for Chemistry and Petrochemistry (ICECHIM), Bucharest, Romania \\ ${ }^{2}$ University POLITEHNICA of Bucharest, Romania
}

Received: 12 July 2017

Accepted: 16 October 2017

\begin{abstract}
Environmental protection draws great attention worldwide due to the release of various harmful pollutants that represent risks or threats to animals and humans. Among these pollutants, endocrinedisrupting chemicals (EDCs) as environmental contaminants interfere with the normal hormonal functions in wildlife and humans. This study proposes multi-walled carbon nanotubes - (MWCNTs) pristine and oxidized, and weathered for one year in environmental conditions - as sorbents for bisphenol A (BPA) from aqueous solution. Kinetic and isotherm models are examined. Better sorption capacities are shown for the functionalized MWCNTs- $\mathrm{COOH}$ because of the two types of predominating interactions that take place: electrostatic and $\pi-\pi$ interactions. The Langmuir isotherm model fit better than the Freundlich one, showing that the adsorption of BPA on MWCNTs is a monolayer adsorption on homogeneous surfaces.
\end{abstract}

Keywords: sorption, BPA, carbon nanotubes

\section{Introduction}

Environmental protection draws great attention worldwide due to the release of various organic and inorganic pollutants, because these pollutants might cause critical environmental problems [1]. Endocrinedisrupting chemicals (EDCs) are environmental contaminants that interfere with the normal hormonal functions in wildlife and humans [2-4]. The wide range of chemicals reported as EDCs include some phenol compounds, among which bisphenol A (BPA) has received more attention due to its use as one of the most produced compounds worldwide [5-9].

*e-mail: ac_ion@yahoo.com
The major concern in the control of BPA is its use in the manufacture of materials that come into contact with foods, such as water bottles, cans, and containers for food, among many others, which are the major sources of human exposure [10-11].

Adsorption is used in water treatment for heavy metals, EDCs, for the control of taste, odor and color. Various adsorbents are widely employed for research, among which carbon-based nanomaterials have been extensively studied in recent years [12]. Carbon nanotubes (CNTs) are relatively new adsorbents of trace pollutants from water, because they have a good specific surface area and small, hollow, and layered structures. These structures have drawn special attention due to their unique physicochemical properties and the variety of potential applications. CNTs have 
shown high adsorption capacities for organic micro pollutants, microorganisms, heavy metals, and organic chemicals. Hence, CNTs would also have good potential for removing BPA from aqueous solutions [13-17].

Carbon nanotubes are carbon allotropes with an aromatic surface when the carbon atoms are in a $\mathrm{sp}^{2}$-like hybridization rolled up in a tubular structure (1D system) with unique mechanical, electrical, magnetic, optical, and thermal properties [18]. The structural properties of CNTs allow for a strong interaction with organic molecules through forces such as hydrogen bonding, $\pi-\pi$ stacking, electrostatic, van der Waals, and hydrophobic interactions [19]. In addition, modified carbon nanotubes also adsorb phenol molecules by $\pi-\pi$ interactions between carbonyl groups and aromatic rings [20].

This study proposes multi-walled carbon nanotubes (MWCNTs) - pristine and oxidized weathered for one year in environmental conditions - as sorbents for bisphenol A (BPA) from aqueous solution. Kinetic and isotherm models are examined.

\section{Materials and Methods}

\section{Materials}

The adsorbents used in this study included two types of multi-walled carbon nanotubes (MWCNTs): MWCNT Sigma Aldrich (110-170 $\mathrm{nm} \times 5-9 \mu \mathrm{m})$ and functionalized MWCNT-COOH Sigma Aldrich (95 $\mathrm{nm} \times 15 \mu \mathrm{m})$.

Bisphenol A (minimum purity 99\%) was the selected sorbate for this study and it was purchased from Fluka/Sigma-Aldrich Chemical, Germany. HPLC-grade methanol was purchased from VWR Chemicals in France. Stock reference solutions were individually prepared in methanol, and kept in the refrigerator for not more than three months. All working reference solutions were freshly prepared prior to use. Aqueous solutions were prepared using HPLC-grade water.

\section{Preparation of BPA Solutions}

The concentrated stock standard solution of $1,000 \mathrm{mg} / \mathrm{LBPA}$ was prepared in amber volumetric flasks using methanol as a solvent. The stock solution was stored at $2-8^{\circ} \mathrm{C}$ up to one week. The working standard solutions were daily prepared by diluting aliquots of the concentrated stock standard into volumetric flasks containing HPLC-grade water.

For the quantification of bisphenol A we used an external standard calibration method. The calibration curve was constructed by plotting the peak area of BPA from the chromatograms of the working standard solutions versus the concentration of analyte per sample. The concentration range of the linearity calibration curve was between $1 \mathrm{mg} / \mathrm{L}$ and $60 \mathrm{mg} / \mathrm{L} \mathrm{BPA}$.

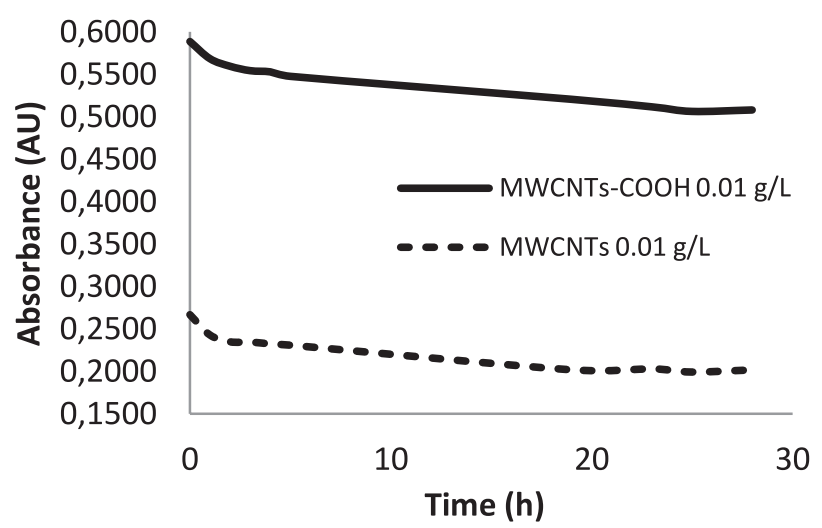

Fig. 1. The absorbance intensities of aqueous suspensions of the studied MWCNTs over a $28 \mathrm{~h}$ period for a methanol:water ratio of 10:90 and a concentration of $0.01 \mathrm{~g} / \mathrm{L}$.

\section{HPLC Analytical Conditions}

HPLC determinations were performed using an Agilent 1100 Series HPLC instrument equipped with a quaternary pump, a degasser, an autosampler, a UV-DAD detector, and Agilent Chemstation software for data acquisition and analysis. The chromatographic parameters were: injection volume $10 \mu \mathrm{L}$; run time $8 \mathrm{~min}$; column temperature $25^{\circ} \mathrm{C}$; column C18 (Zorbax Eclipse Plus-Agilent), $3.5 \mu \mathrm{m}$, $100 \times 4.6 \mathrm{~mm}$ i.d.; flow rate $0.5 \mathrm{~mL} / \mathrm{min}$; and isocratic conditions at 80:20 A:B (v/v), where $\mathrm{A}=$ methanol and $\mathrm{B}=$ HPLC ultrapure water. Prior to each series of chromatographic separation, the analytical column was conditioned for $30 \mathrm{~min}$ with methanol and equilibrated with $(80: 20 \mathrm{v} / \mathrm{v})$ methanol:water. A period of $10 \mathrm{~min}$ of equilibration was required before the next injection. A DAD detector performed monitoring of BPA at $280 \mathrm{~nm}$. Identification was made by comparing this time with the retention time $\left(\mathrm{t}_{\mathrm{R}}\right)$ of BPA from standard solution.

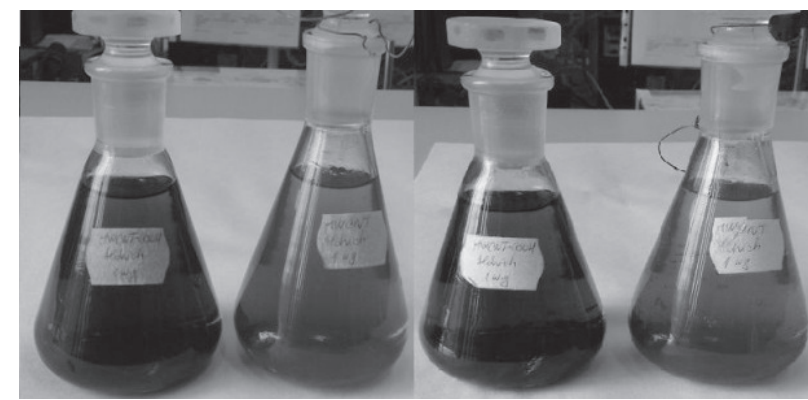
a)
b)
c)
d)

Fig. 2. Image of MWCNT-COOH a, c) and MWCNT b, d) dispersions. 


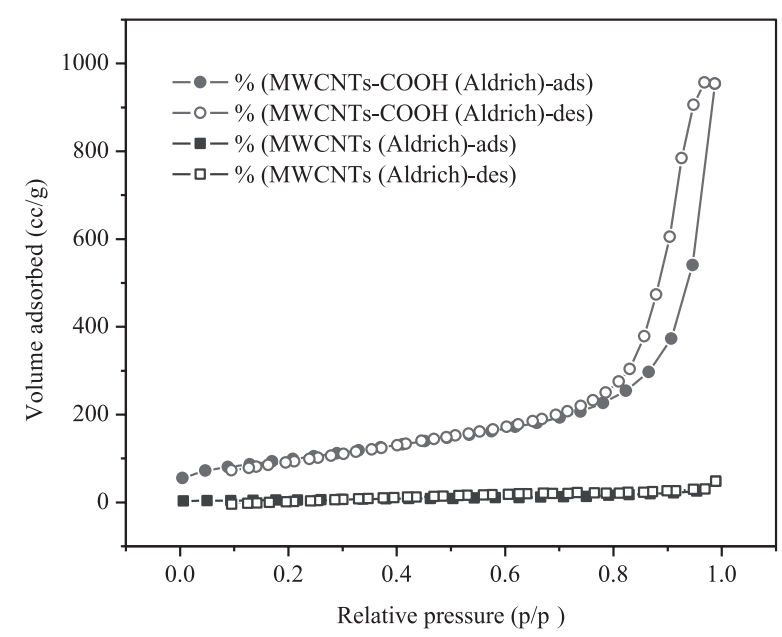

Fig. 3. $\mathrm{N}_{2}$ adsorption-desorption isotherms of pristine MWCNTs and functionalized MWCNT-COOHs.

\section{Batch Adsorption Experiments}

The adsorption experiments were evaluated for different concentration levels of BPA and of weathered carbon nanotubes (CNTs) in environmental conditions. The desired concentrations of BPA were obtained by dilution of the standard solution of $100 \mathrm{mg} / \mathrm{L}$ BPA with $10 \%$ of methanol and $90 \%$ of distilled water, then the solution was added in a closed $100 \mathrm{ml}$ glass pyramid bottle that contained $1 \mathrm{mg}$ of adsorbent. The mixtures were sonicated in an ultrasound bath FRITSCH Laborette Germany type 17.202 No. 963 volt 220. The solutions were filtered into $2 \mathrm{~mL}$ glass vials using $0.45 \mu \mathrm{m}$ PTFE syringe filters and determined the BPA concentration by using a RP-HPLC/UV method at $280 \mathrm{~nm}$. Each treatment was carried out in triplicate. The influences of the contact time and of the initial concentration of BPA were studied and monitored at different concentrations of carbon nanotubes (CNTs) and at different temperatures between 20 and $35^{\circ} \mathrm{C}$.

The BPA rate (\%) and adsorption capacity $(\mathrm{mg} / \mathrm{g})$ were calculated by:

$$
q=\frac{C_{0}-C_{x}}{m} \times V
$$

...where $\mathrm{q}(\mathrm{mg} / \mathrm{g})$ is the BPA adsorption capacity, $\mathrm{C}_{0}$ $(\mathrm{mg} / \mathrm{L})$ and $\mathrm{C}_{\mathrm{x}}(\mathrm{mg} / \mathrm{L})$ are the initial and equilibrium BPA concentrations in the solution, V (L) is solution volume, and $\mathrm{M}(\mathrm{g})$ is the mass of adsorbent.

\section{Characterization of the Nanosorbents}

\section{BET-Specific Surface Areas and Pore Size Distribution}

The Brunauer-Emmet-Teller (BET) specific surface area of the samples was characterized by nitrogen adsorption using a Quantachrome NOVA 2200e instrument. Nitrogen adsorption/desorption isotherms were measured at the temperature of liquid nitrogen $(77 \mathrm{~K})$. Prior to measurements, the samples were degassed at $150^{\circ} \mathrm{C}$ in a vacuum for $4 \mathrm{~h}$.

\section{Dispersion Characterization Using UV-VIS Methods}

The dispersions of functionalized and pristine carbon nanotube in aqueous media and the stability dispersions were tested using a GBC Scientific Equipment Pty. Ltd CINTRA 202 V 3749 UV-Vis spectrometer.

\section{Scanning Electron Microscopy (SEM)}

The morphology of MWCNTs unmodified and with modified surfaces were studied by SEM in the following working conditions: samples were submitted homogeneously in thin layers on conductive surfaces, images dispersed samples prior to submission being taken using a microscope SEM (Philips Quanta Inspect F) coupled with $\mathrm{X}$ radiation source of $30 \mathrm{kV}$ and 2000x magnification.

\section{Fourier-Transformed Infrared Spectrometry (FTIR)}

The determinations were made using a Vertex 70 Brucker FTIR spectrometer equipped with a device for analyzing solid samples by $\mathrm{KBr}$ ( $\mathrm{KBr}$ spectral purity) pressed disc method. FTIR spectra were recorded between 4,000-400 $\mathrm{cm}^{-1}$ with a resolution of $4 \mathrm{~cm}^{-1}$, in the same conditions being recorded and compared with the spectrum of pure $\mathrm{KBr}$.

\section{Thermogravimetric Analysis (TGA)}

TGA analysis was performed using a Perkin-Elmer Diamond thermal analyzer TG/DTA in the temperature range $20-800^{\circ} \mathrm{C}$ using a heating rate of $20^{\circ} \mathrm{C} / \mathrm{min}$ in a nitrogen stream of $200 \mathrm{ml} / \mathrm{min}$.

Table 1. Characteristics of the structure of the nanomaterials used in this study.

\begin{tabular}{|c|c|c|c|c|c|}
\hline Nanomaterial & Purity, $\%$ & Structural parameters & $\begin{array}{c}\text { Specific surface area } \\
\left(\mathrm{m}^{2} / \mathrm{g}\right)\end{array}$ & $\begin{array}{c}\text { Pore volume } \\
\left(\mathrm{cm}^{3} / \mathrm{g}\right)\end{array}$ & $\begin{array}{c}\text { Pore diameter } \\
(\mathrm{nm})\end{array}$ \\
\hline MWCNTs & $>90 \%$ & LxD $110-170 \times 5-9, \mathrm{~nm}$ & 182.28 & 0.073 & 3.231 \\
\hline MWCNTs-COOH & $>85 \%$ & LxD $9.5 \times 1.5 \mathrm{~nm}$ & 255.45 & 1.413 & 3.158 \\
\hline
\end{tabular}


Table 2. Effects of the various interactions on the adsorption of organic contaminants on carbon nanostructures.

\begin{tabular}{|c|c|c|}
\hline Sorbent & Adsorption mechanism & Reference \\
\hline MWCNTs & $\begin{array}{c}\text { Electrostatic } \\
\text { interactions, hydrogen } \\
\text { bonds }\end{array}$ & {$[21]$} \\
\hline MWCNTs-COOH & $\begin{array}{c}\mathrm{pH} \text { of the solution, } \\
\text { ionic strength, solvent } \\
\text { polarity }\end{array}$ & {$[22]$} \\
\hline
\end{tabular}

\section{Results and Analysis}

\section{Characterization of the Nanosorbents}

The initial optical density can be taken as a measure of the mass of dispersed tubes by sonication, progressively reduced during $28 \mathrm{~h}$, after this period remaining constant. The optical density at $28 \mathrm{~h}$ was considered as a measure of the innate stability of the tube suspension after settling, or without agitation. Based on these measurements, it was observed that the most efficient methanol/water (v/v) ratio was 10:90. The UV-Vis spectra of MWCNTs dispersed in solutions with different concentrations showed that by increasing the concentrations of dispersed MWCNTs results in increased absorbance intensities. All intensities at different wavelengths increased by increasing the concentration of dispersed MWCNTs (Fig. 1).

Digital pictures (Fig. 2) were taken to display the dispersion quality of MWCNTs-COOH and MWCNTs immediately after sonication and after $28 \mathrm{~h}$. Functionalized carbon nanotubes show better dispersion than MWCNTs. The existence of oxygen-containing groups in the MWCNTs results in higher surface energy. The stability of functionalized and pristine carbon nanotube dispersions in aqueous media with respect to time and their optical density (absorbance) was monitored in real-time at initial MWCNTs and MWCNTs-COOH concentrations of $0.01 \mathrm{~g} / \mathrm{L}$ in methanol: water-solvent mixtures. The dispersions were sonicated in an ultrasound bath for 30 minutes and then centrifuged. The supernatant was collected for analysis.
$B E T$

$\mathrm{N}_{2}$ adsorption-desorption isotherms are presented in Fig. 3. The specific surface area was calculated according to the BET equation. The total pore volume was estimated from the amount of gas adsorbed at $\mathrm{p} / \mathrm{p}_{\mathrm{o}}=0.99$. Pore size distribution was constant as indicated by the producer and calculated from the desorption branch of the isotherm using the BarrettJoyner-Halenda (BJH) method [20]. MWCNTs-COOH showed a type IV isotherm, classified by IUPAC, a BET-specific surface of $255.44 \mathrm{~m}^{2} / \mathrm{g}$, an average pore volume of $1.41 \mathrm{~cm}^{3} / \mathrm{g}$, and a pore diameter of $3.15 \mathrm{~nm}-$ which does not allow the BPA molecules to access at the internal surface of the MWCNTs (Table 1).

\section{SEM}

The morphology of carbon nanostructures studied both the pristine and the functionalized, simple and impregnated with BPA is presented in Fig. 4, observing that MWCNTs shows a homogeneous distribution of the tubes. Compared with the pristine MWCNTs, the ones functionalized with carboxyl group indicate the presence of fragments on external walls of nanotubes probably due to the carboxyl fragments from the structure of nanotubes. These interactions have been partially studied in the literature, being shown in Table 2.

Study of MWCNTs simple and impregnated with BPA by scanning electron microscopy indicated the presence of a compact layer that covers the surface with BPA. BPA molecule can interact through hydrogen bonds with the surface of the nanotubes with only one hydroxyl group and $\pi-\pi$ interaction, or it may interact through two hydrogen bonds with both hydroxyl groups, but without $\pi-\pi$ interaction. In the case in which a hydroxyl group remains available, it can form hydrogen bonds with the spherical surface of another molecule of BPA, forming a layer more compact of impregnation.

\section{FTIR}

FTIR spectra of studied nanostructures, simple and impregnated, indicate the presence of BPA

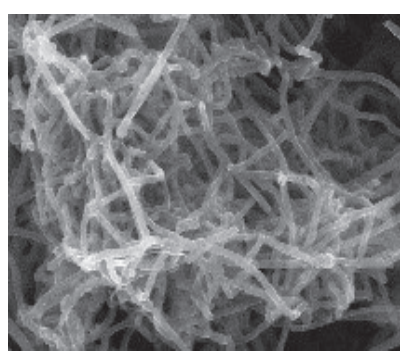

a)

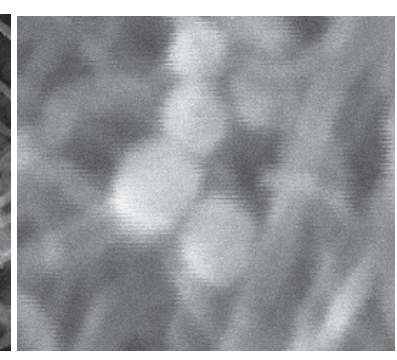

b)

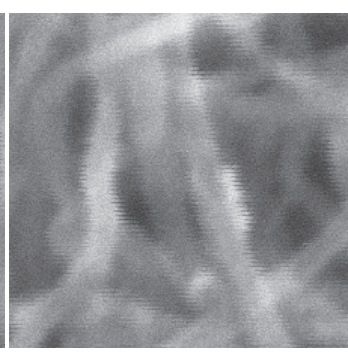

c)

Fig. 4. SEM images of MWCNTs pristine and - $\mathrm{COOH}$ impregnated with BPA: a) BPA MWCNTs; b) BPA - MWCNTs-COOH; c) MWCNTs-COOH. 

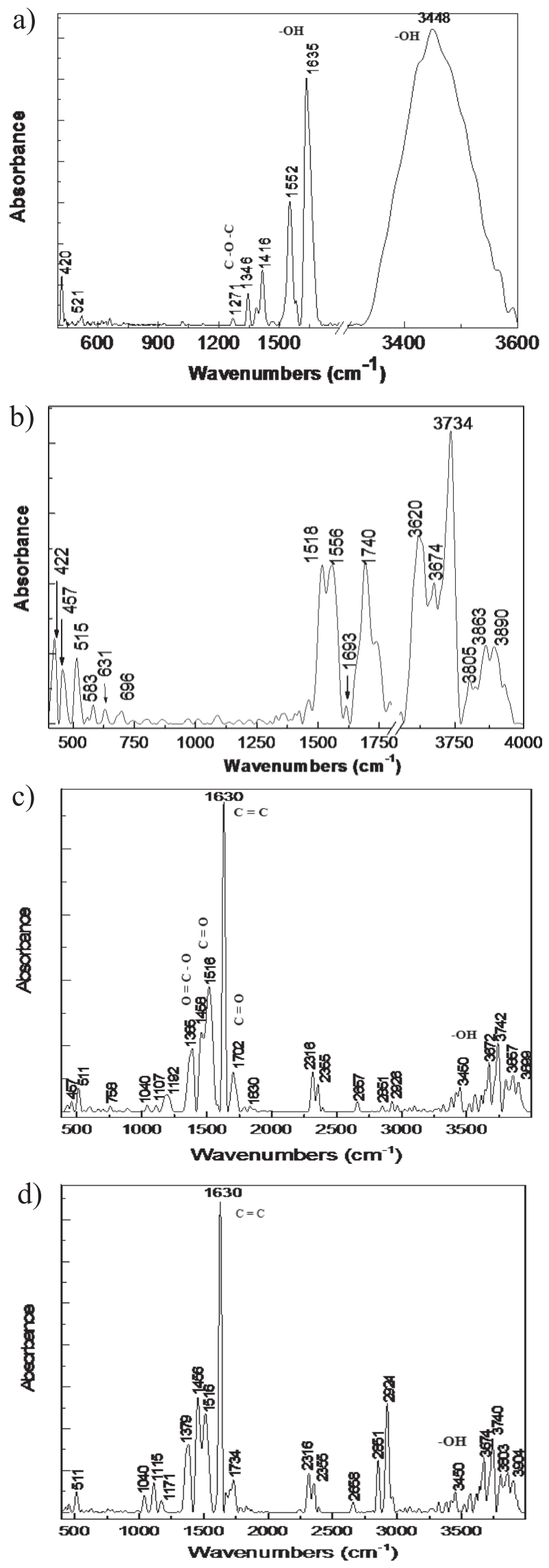

Fig. 5. FTIR spectra of MWCNTs and MWCNTs-COOH; spectra a), c) before and spectra b), d) after the BPA sorption. molecules on the surface of simple and oxidized MWCNTs. MWCNTs have two dominant absorption bands at 1,635 and $3,448 \mathrm{~cm}^{-1}$, associated $-\mathrm{OH}$ groups and a specific band for MWCNTs at $1,416 \mathrm{~cm}^{-1}$ (Fig. 5a). We can observe the presence of bands specific to these compounds in samples of MWCNTs impregnated with BPA (Fig. 5b). The bands that appear in the presented spectra can be assigned to the following functional groups: at $3,448 \mathrm{~cm}^{-1}$ to the stretching vibration of $-\mathrm{OH}$ groups; at $1,702 \mathrm{~cm}^{-1}$ to the double bonds $\mathrm{C}=\mathrm{O}$ of the carboxyl groups; at $1,622 \mathrm{~cm}^{-1}$ to the skeleton vibration of $\mathrm{C}=\mathrm{C}$ double bonds from the aromatic ring; at approx. $1,386 \mathrm{~cm}^{-1}$ to $\mathrm{O}=\mathrm{C}-\mathrm{O}$ bonds and at $1,271 \mathrm{~cm}^{-1}$ to $\mathrm{C}-\mathrm{O}-\mathrm{C}$ bonds; and at $1,040 \mathrm{~cm}^{-1}$ to $\mathrm{C}-\mathrm{O}$ alkoxy groups (Fig. 5c). From the presented FTIR spectra it can be noted that in pristine MWCNTs the absorption band at 3,448 $\mathrm{cm}^{-1}$ corresponding to stretching vibration of $-\mathrm{OH}$ decreases, and the bond at $1,192 \mathrm{~cm}^{-1}$ attributed to the stretching vibration of the $\mathrm{C}-\mathrm{O}$ bond is reduced. The skeleton vibration of the $\mathrm{C}=\mathrm{C}$ bond from the aromatic ring appears at 1,630 and $1,516 \mathrm{~cm}^{-1}$.

After the BPA adsorption, new FTIR bands appear in the ranges 2,800-3,000 $\mathrm{cm}^{-1}$ and $400-1,800 \mathrm{~cm}^{-1}$, indicating that BPA molecules were adsorbed on the carbon nanostructure surface. The vibration frequencies of the $-\mathrm{OH}$ group move from 3,448 to $3,430 \mathrm{~cm}^{-1}$, movement that can be associated with the formation of hydrogen bonds between the hydroxyl groups both from BPA molecule and oxidized nanostructures. In a small amount these groups exist also in pristine carbon-based nanostructures. The peak corresponding to the skeleton vibration of $\mathrm{C}=\mathrm{C}$ double bond from aromatic ring are shifted from $1,633 \mathrm{~cm}^{-1}$ to $1,641 \mathrm{~cm}^{-1}$, being narrowed after adsorption, which could indicate a $\pi-\pi$ interaction between benzene rings from BPA molecules and those of studied nanostructures (Fig. 5d).

From FTIR spectra we observed the possibility of highlighting the interactions that occur between the surfaces of the studied carbon nanostructures (MWCNTs, MWCNTs-COOH) and the BPA molecules. Because BPA molecules contain two benzene rings, it can be assumed that the main intermolecular forces will be $\pi-\pi$ interactions. Also, residual groups containing oxygen that can exist in the non-oxidized nanostructures may also form hydrogen bonds with the hydroxyl groups of BPA. Among the studied molecules and the used nanostructures could appear two types of interactions: one based on $\pi-\pi$ interactions between the benzene rings of the sorbate-sorbent system and the other on the hydrogen bonds between the oxygen-containing groups.

\section{$T G A$}

The measured parameters in the TGA curves are initial temperature, the temperature of oxidation, and residual mass. The initial temperature represents the temperature at which the material begins to decompose, oxidation temperature is considered the temperature at which the material shows the maximum loss of 

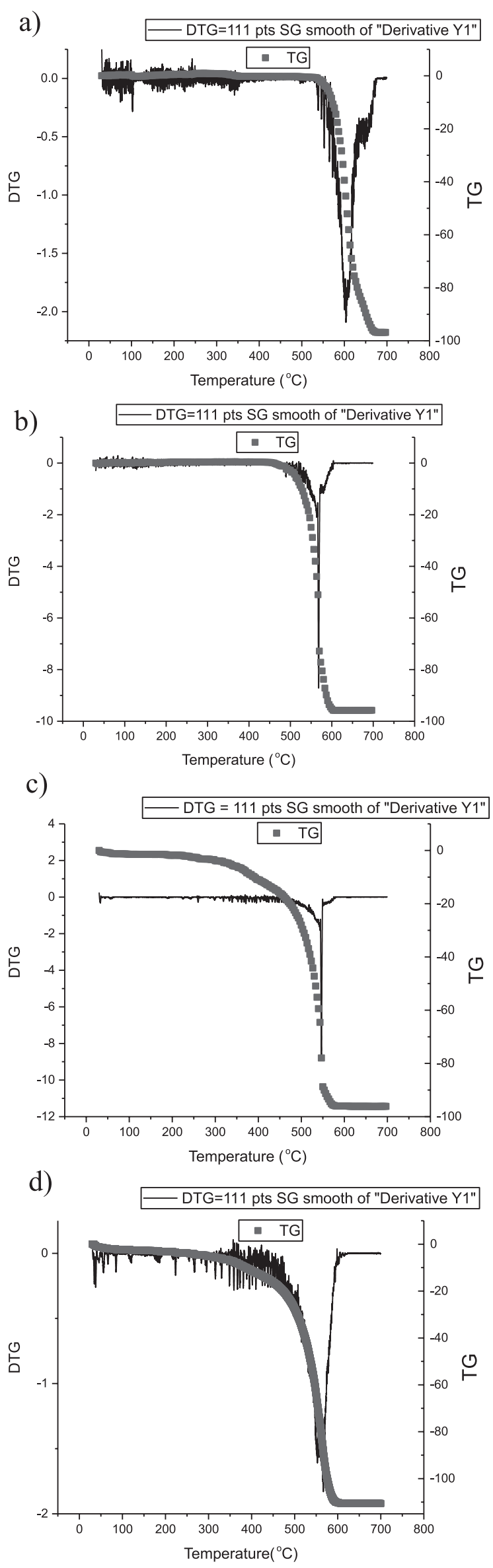

Fig. 6. TGA analysis for MWCNTs and MWCNTs-COOH after $a, c)$ and before $b, d)$ the sorption of BPA.

a)

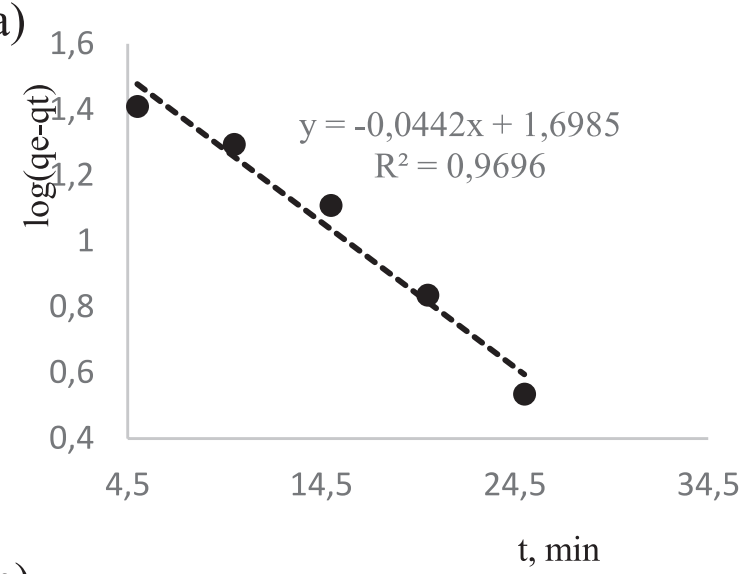

b)

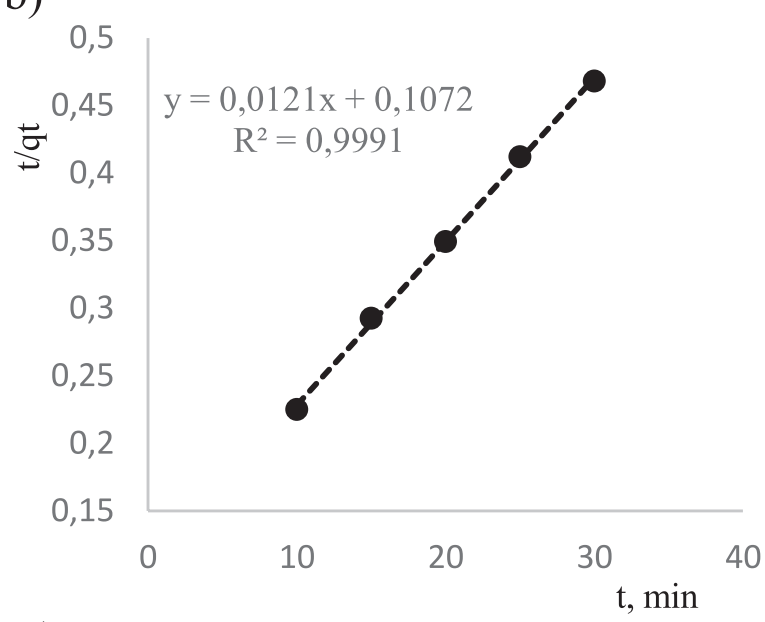

c) 2

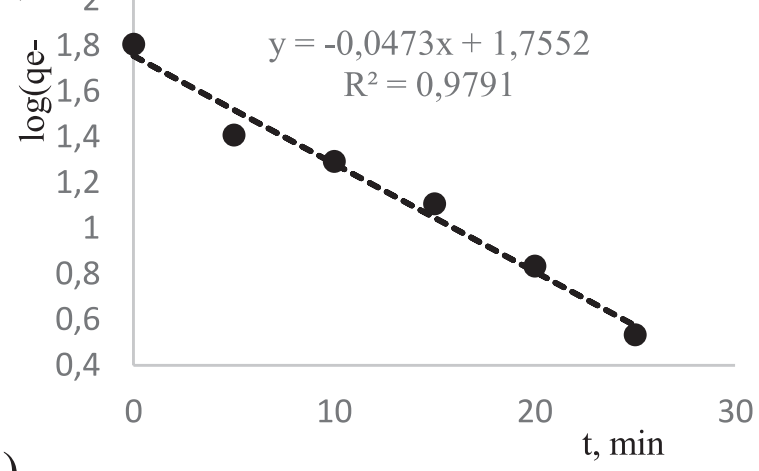

d)

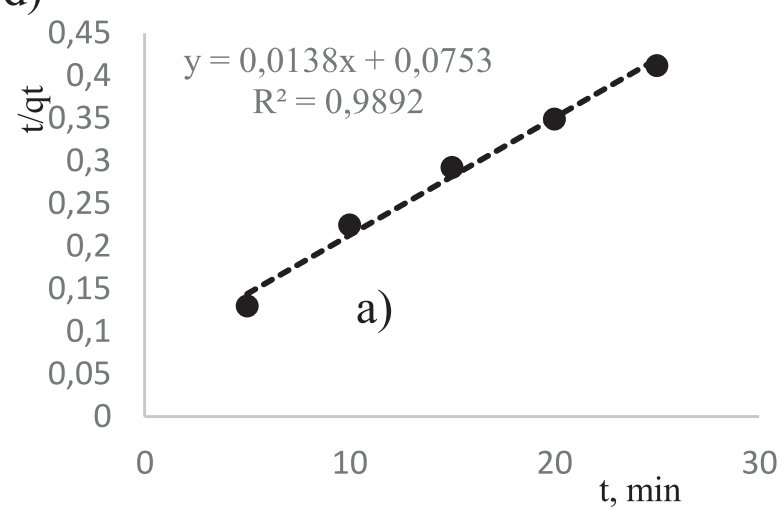

Fig. 7. Adsorption kinetic models (pseudo first-order and pseudo-second models) of BPA on MWCNTs (a, b) and MWCNTs-COOH (c, d); conditions: $\mathrm{C}_{\mathrm{i}}=10 \mathrm{mg} / \mathrm{L}$ BPA, $\mathrm{T}=20{ }^{\circ} \mathrm{C}, \mathrm{V}=100 \mathrm{~mL}$, contact time 3 hours, equilibrium reached after 30 minutes. 
Table 3. Kinetic parameters for the adsorption of BPA by MWCNTs and MWCNTs COOH (pseudo first- and second-order models).

\begin{tabular}{|c|c|c|c|c|c|c|c|}
\hline \multirow{2}{*}{ Sorbent } & \multirow{2}{*}{$\mathrm{q}_{\mathrm{e}}, \exp (\mathrm{mg} / \mathrm{g})$} & \multicolumn{3}{|c|}{ Pseudo first-order } & \multicolumn{3}{c|}{ Pseudo second-order } \\
\cline { 3 - 9 } & & $\mathrm{K}_{1}(\mathrm{~L} / \mathrm{min})$ & $\mathrm{q}_{\mathrm{e}}$, calc $(\mathrm{mg} / \mathrm{g})$ & $\mathrm{R}^{2}$ & $\mathrm{q}_{\mathrm{e}}, \mathrm{calc}(\mathrm{mg} / \mathrm{g})$ & $\mathrm{K}_{2}(\mathrm{mg} / \mathrm{g} / \mathrm{min})$ & $\mathrm{R}^{2}$ \\
\hline MWCNTs & 64.10 & 0.1017 & 49.94 & 0.9696 & 93.2935 & 0.0114 & 0.9991 \\
\hline MWCNTs-COOH & 60.68 & 0.1088 & 56.91 & 0.9799 & 101.46 & 0.0097 & 0.9370 \\
\hline
\end{tabular}

mass being an indication of the thermal stability of the material and the residual mass is the quantity of material remaining after heating, depending on the metallic catalyst used and on the oxidation products. Residual masses can represent up to $50 \%$ of the analyzed material, depending on its purity and homogeneity (Fig. 6).

C-MNMs are typically stable at temperatures up to $600^{\circ} \mathrm{C}$ with mass loss of 3-4\%. MWCNTs-COOH show higher losses of $11-13 \%$ due to the presence of oxygen-functional groups. Thermal degradation of modified MWCNTs is a stepwise process due to various functional groups existing on the surface of the nanostructures. The first mass loss for all samples analyzed that can occur at temperature values less than $200^{\circ} \mathrm{C}$ is attributed to nanomaterials saturated with water vapor. At higher values of the temperature, the mass loss may be due to thermal decomposition of the functional groups. TGA analysis indicates that in the case of MWCNTs no significant loss of mass between 100 and $200^{\circ} \mathrm{C}$ is observed, meaning that inclusion water molecules are absent from their crystalline lattice. The thermal stability of MWCNTs can be attributed in the case of MWCNTs to the bonds from aromatic rings, being affected by the number of walls of the nanotubes, by the nature of the catalyst used in their synthesis, and by defects in the material. TGA curves show mass loss at $550^{\circ} \mathrm{C}$ for simple MWCNTs (Fig. 6b) and $575^{\circ} \mathrm{C}$ for MWCNTs- $\mathrm{COOH}$ (Fig. 6d). In the case of carbon nanostructures impregnated with BPA, the temperature rises to $600^{\circ} \mathrm{C}$ for MWCNTs (Fig. 6a) and drops to $550^{\circ} \mathrm{C}$ for $\mathrm{MWCNTs}-\mathrm{COOH}$ impregnated with BPA (Fig. 6c).

\section{Kinetic Analysis of BPA Sorption Process}

Typically, various mechanisms govern adsorption kinetics; the most limiting are the diffusion mechanisms such as external diffusion, boundary layer diffusion, and intra-particle diffusion. An adsorption kinetic study was obtained with an initial BPA concentration of $10 \mathrm{mg} / \mathrm{L}$ la $20^{\circ} \mathrm{C}, \mathrm{pH} 6$ to determine the time required for adsorption to reach equilibrium (Fig. 7). The concentrations of BPA were measured at different times between 15 and $180 \mathrm{~min}$.

The parameters of the kinetic models are presented in Table 3. The pseudo-first model was proved to better fit with the experimental data. Based on the results, it can be assumed that the adsorption kinetics process consists of several stages: the first being a fast diffusion of the BPA molecules onto the MWCNT surface. Taking into account the pore diameter, it seems that the BPA molecules remain on the external surface of the MWCNTs until a dynamic equilibrium is approached, then get desorbed into solution. Better sorption capacities are shown for the functionalized MWCNTs$\mathrm{COOH}$ because of the two types of interactions that take place, electrostatic and $\pi-\pi$ interactions, the last ones predominating.

\section{BPA Adsorption Isotherms}

The adsorption study describes the interactions between the sorbent and the organic contaminant BPA. The equilibrium data were fitted with Langmuir and Freundlich models (Fig. 8) at three temperatures and at five initial concentrations of BPA.

The first one assumes monolayer adsorption on homogeneous surfaces and the second describes a multilayer adsorption on heterogeneous surfaces.

The isotherm parameters are listed in Table 4 . Based on the comparison of the correlation coefficients value, the Langmuir isotherm model fit better than the Freundlich one, showing that the adsorption of BPA on MWCNTs is a monolayer adsorption on homogeneous surfaces.

\section{Thermodynamic Studies}

Thermodynamic parameters for adsorption of BPA on MWCNTs and on MWCNTs-COOH are presented in Table 5.

The values of $\Delta \mathrm{H}^{0}$ of -43.52 and $-49.19 \mathrm{~kJ} \mathrm{~mol}^{-1}$ can be associated with both chemical and physical sorption processes, which is also possible on pristine MWCNTs because of the residual oxygen-containing groups remaining after synthesis. It is an exothermic process for both pristine and carboxyl-containing MWCNTs. All the $\Delta G^{0}$ values were negative accompanied by positive $\Delta \mathrm{S}^{0}$ values, showing that the adsorption process was spontaneous, with a good affinity for BPA. The decrease of the $\Delta \mathrm{G}^{0}\left(\mathrm{~kJ} \mathrm{~mol}^{-1}\right)$ by increasing the temperature shows an efficient adsorption at lower temperatures. The negative values of $\Delta \mathrm{H}^{0}$ show that the adsorption process was exothermic.

\section{Effect of $\mathrm{pH}$}

Theoretically, an important factor that affects the adsorption of BPA on the sites of CNTs is $\mathrm{pH}$. This 
a)

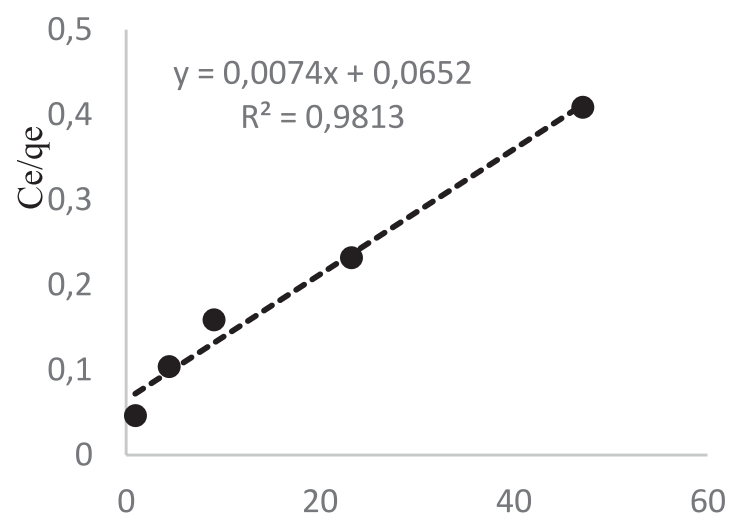

b)
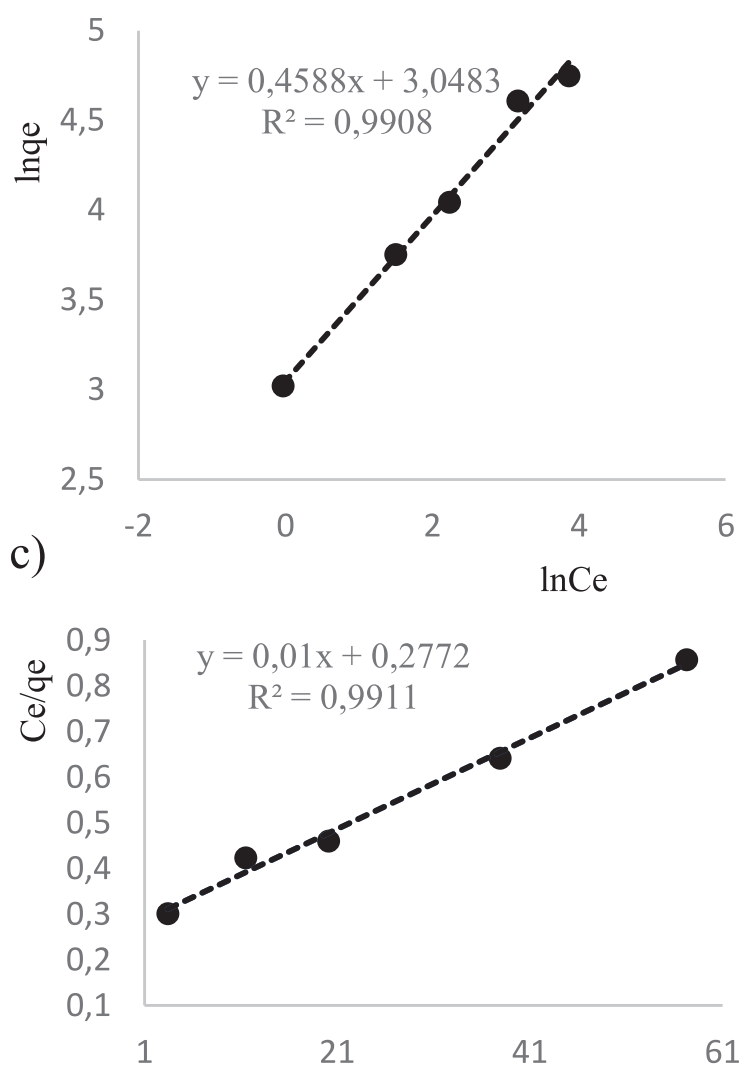

d)

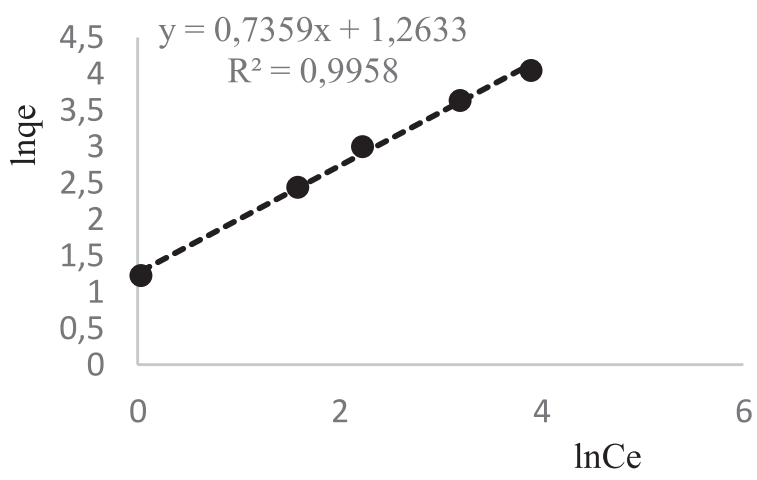

Fig. 8. Langmuir and Freundlich adsorption models of BPA on MWCNTs a, b) and on MWCNTs-COOH c, d); conditions: $\mathrm{C}_{\mathrm{i}}=1-50 \mathrm{mg} / \mathrm{L} \mathrm{BPA}, \mathrm{t}=25^{\circ} \mathrm{C}, \mathrm{V}=100 \mathrm{~mL}$, contact time 3 hours, equilibrium reached after 30 minutes. parameter can affect both the electrical surface charges of the adsorbent and the dissociation of the sorbate. The effect of $\mathrm{pH}$ differs depending on the type of adsorbents and the dissociation constants $\left(\mathrm{p}_{\mathrm{Ka}}\right)$ of the sorbate. In aqueous solutions the sorbate will stay in the molecular form at $\mathrm{pH}$ lower than $\mathrm{p}_{\mathrm{Ka}}\left(\mathrm{p}_{\mathrm{Ka}}\right.$ of $\left.\mathrm{BPA}=9.6-10.2\right)$ and will lose their protons at $\mathrm{pH}$ above $\mathrm{P}_{\mathrm{Ka}}$. Thus, at $\mathrm{pH}$ of around or higher than $\mathrm{p}_{\mathrm{Ka}}$, the molecules of BPA are deprotonated to bisphenolate anions $\left(\mathrm{HBPA}^{-}\right.$and $\left.\mathrm{BPA}^{2-}\right)$ and cause electrostatic repulsion with negatively charged sorbent.

The dependence of adsorption on $\mathrm{pH}$ is due to the dependence of the surface charge of CNTs on $\mathrm{pH}$. The relevant experiments demonstrated that the adsorption capacity of BPA on the surface of CNTs fluctuates very little over the $\mathrm{pH}$ range $3-9$, indicating the high stability of CNTs as adsorbent for BPA over a rather wide range of $\mathrm{pH}$.

\section{Adsorption Mechanism}

The appearance of oxygen-containing groups favors adsorption, the results being supported by the structures of sorbate and adsorbent. The molecule of BPA contains hydrophilic hydroxyl groups and a hydrophobic benzene ring, the corroboration between hydrogen bonding, and the $\pi-\pi$ interactions is shown to be stronger than the adsorption on pristine MWCNTs. The maximum adsorption capacity of BPA on MWCNTs-COOH amounted to 100.29 , in comparison with 95.13 for MWCNTs. A possible explanation can relate to the stronger interactions in the first case, increased by the oxygen content because of the enhanced H-bond or electron-donor acceptor interactions. A comparison of the adsorption capacities of MWCNTs determined in other studies is presented in Table 6 .

\section{Conclusions}

In this study, commercially available pristine and functionalized multiwalled carbon nanotubes (MWCNTs) were evaluated for the removal of bisphenol $\mathrm{A}$ in aqueous solutions.

Due to good adsorption capacity, the CNTs may be considered as alternative adsorbents for removing organic contaminants from water in an engineering application. The adsorption could be interpreted based on the large number of available active sites, which helps the transfer of BPA to CNTs.

The adsorption process was characterized by FTIR and TGA analysis on MWCNTs pristine and MWCNTs$\mathrm{COOH}$ before and after BPA adsorption.

In this study, a UV-Vis spectroscopic technique to monitor the dispersion of MWCNTs in aqueous solutions was also presented. The results show that maximum achievable dispersion corresponds to the maximum UV-Vis absorbance of the MWCNTs fresh solution. Based on these results, a UV-Vis absorbance 
Table 4. Isotherm parameters for the adsorption of BPA by MWCNTs and MWCNTs COOH at different temperatures.

\begin{tabular}{|c|c|c|c|c|c|c|}
\hline \multirow{2}{*}{ Sorbent } & \multicolumn{3}{|c|}{ Langmuir } & \multicolumn{3}{c|}{ Freundlich } \\
\cline { 2 - 8 } & $\mathrm{q}_{\mathrm{m}}, \mathrm{mg} / \mathrm{g}$ & $\mathrm{K}_{\mathrm{L}}, \mathrm{L} / \mathrm{mg}$ & $\mathrm{R}^{2}$ & $\mathrm{~K}_{\mathrm{F}}$ & $\mathrm{n}$ & $\mathrm{R}^{2}$ \\
\hline MWCNTs & 95.13 & 0.1138 & 0.9813 & 21.08 & 2.1834 & 0.9908 \\
\hline MWCNTs-COOH & 100.29 & 0.0359 & 0.9910 & 3.53 & 1.3605 & 0.9958 \\
\hline
\end{tabular}

Table 5. Thermodynamic parameters for adsorption of BPA on MWCNTs and on MWCNT-COOHs.

\begin{tabular}{|c|c|c|c|c|c|}
\hline \multirow{2}{*}{$\begin{array}{c}\text { Thermodynamic } \\
\text { parameter }\end{array}$} & $\Delta \mathrm{H}^{0}\left(\mathrm{~kJ} \mathrm{~mol}^{-1}\right)$ & $\Delta \mathrm{S}^{0}\left(\mathrm{~J} \mathrm{~mol}^{-1} \mathrm{~K}^{-1}\right)$ & \multicolumn{3}{|c|}{$\Delta \mathrm{G}^{0}\left(\mathrm{~kJ} \mathrm{~mol}^{-1}\right)$} \\
\cline { 3 - 6 } & & & 293 & 298 & $303 \mathrm{~K}$ \\
\hline MWCNTs & -43.52 & 33.12 & -5.51 & -5.69 & -5.84 \\
\hline MWCNTs-COOH & -49.19 & 34.71 & -5.42 & -5.60 & -5.76 \\
\hline
\end{tabular}

Table 6. Adsorption capacity of BPA by CNTs and graphene in the literature.

\begin{tabular}{|c|c|c|c|c|c|c|}
\hline Adsorbent & $\mathrm{T}\left({ }^{\circ} \mathrm{C}\right)$ & $\begin{array}{c}\text { Sorbent/ } \\
\text { solution }(\mathrm{w} / \mathrm{v}) \text { ratios }\end{array}$ & Contact time & $\mathrm{pH}$ & $\mathrm{C}_{\mathrm{s}}(\mathrm{mg} / \mathrm{g})$ & $\mathrm{Ref}$. \\
\hline $\begin{array}{c}\text { SWCNT } \\
\text { (single-walled carbon nanotubes) }\end{array}$ & 20 & $1 \mathrm{mg} / 255 \mathrm{~mL}$ & one week & - & 126.1 & {$[23]$} \\
\hline $\begin{array}{c}\text { MWCNT } \\
\text { (multi-walled carbon nanotubes) }\end{array}$ & 20 & $1 \mathrm{mg} / 255 \mathrm{~mL}$ & one week & - & 29.8 & {$[23]$} \\
\hline MWCNT & 27 & $0.125 \mathrm{~g} / 1 \mathrm{~L}$ & $3 \mathrm{~h}$ & 6 & 26.94 & {$[24]$} \\
\hline MWCNT & 27 & $0.125 \mathrm{~g} / 1 \mathrm{~L}$ & $24 \mathrm{~h}$ & 6 & 59.17 & {$[24]$} \\
\hline SWCNT & 20 & $0.5 \mathrm{~g} / 1 \mathrm{~L}$ & $60 \mathrm{~min}$. & 9 & 71 & {$[25]$} \\
\hline MWCNT & 20 & $0.5 \mathrm{~g} / 1 \mathrm{~L}$ & $60 \mathrm{~min}$. & 9 & 111.0 & {$[25]$} \\
\hline GO (graphene oxide) & 25 & $10 \mathrm{mg} / 50 \mathrm{~mL}$ & $60 \mathrm{~min}$. & 3.5 & 49.26 & {$[26]$} \\
\hline GO & 25 & $10 \mathrm{mg} / 100 \mathrm{~mL}$ & $30 \mathrm{~min}$. & 6 & 87.80 & {$[27]$} \\
\hline
\end{tabular}

intensity at $280 \mathrm{~nm}$ was chosen as reference for estimating the stability of the two types of dispersed nanotubes, MWCNTs-COOH and MWCNTs, over a period of $28 \mathrm{~h}$.

Better sorption capacities are shown for the functionalized MWCNTs-COOH because of the two types of predominating interactions that take place, electrostatic and $\pi-\pi$ interactions. The Langmuir isotherm model fit better than the Freundlich one, showing that the adsorption of BPA on MWCNTs is a monolayer adsorption on homogeneous surfaces.

An important factor that affects adsorption kinetics is the initial concentration of the sorbate. The adsorption capacity of BPA increases by increasing the initial BPA concentration. This tendency could be explained by a larger driving force provided by the higher BPA concentration, which could defeat the mass transfer resistance between the aqueous and solid phases.

We also observed that decreasing the sorbent dosage from $1 \mathrm{mg}$ to $0.1 \mathrm{mg}$ increases adsorption capacity. This observation may be attributed to the excess of the active sites of the adsorbent, as compared to the saturated threshold adsorption points, which lead to a partial occupation of the active sites by the BPA molecules, to which the overlapping and aggregation of the solid that can block the adsorption sites can also contribute.

\section{Acknowledgements}

This research was performed within the framework of ERA-NET SIIN funded by the European Commission within the $7^{\text {th }}$ Framework Program and supported by the Romanian Executive Agency for Higher Education and RDI Funding (Unitatea Executiva pentru Finantarea Invatamantului Superior, Cercetarii, Dezvoltarii si Inovarii: UEFISCDI) 


\section{Supplementary material}

\section{A Sorption Study of Bisphenol A in Aqueous \\ Solutions on Multiwalled Carbon Nanotubes Pristine and Oxidized}

Raluca Madalina Senin ${ }^{1,2}$, Ion Ion $^{2}$, Alina Catrinel Ion ${ }^{2}$

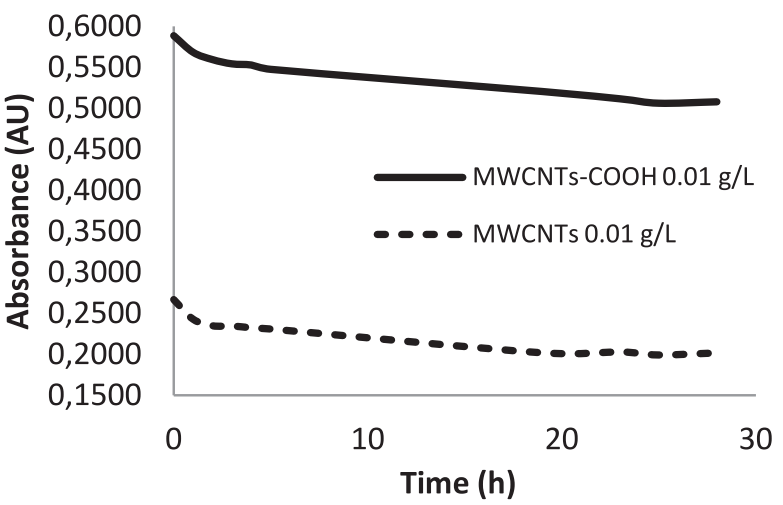

Fig. S1. The absorbance intensities of aqueous suspensions of the studied MWCNTs, over a $28 \mathrm{~h}$ period for a methanol: water ratio of 10:90 and a concentration of $0.01 \mathrm{~g} / \mathrm{L}$.

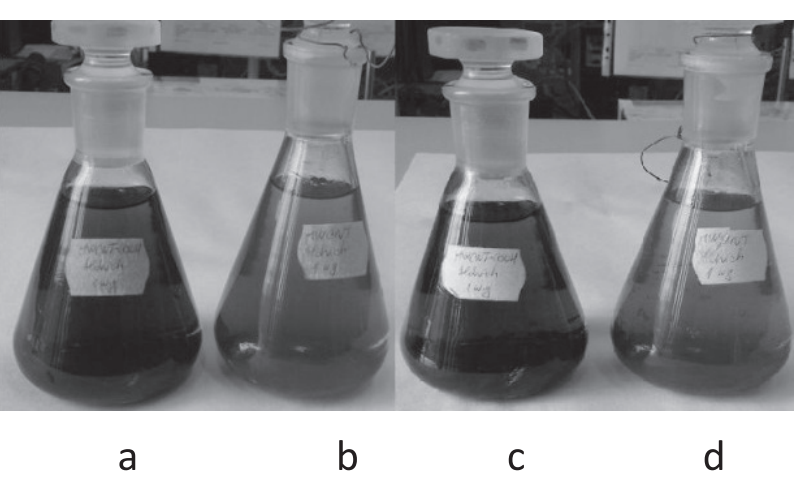

Fig. S2. Digital picture of MWCNTs-COOH (a, c) and MWCNTs (b, d) dispersions.

Procedure: $1 \mathrm{mg}$ of each sample was suspended in $100 \mathrm{~mL}$ of mixture methanol: water (10:90) and the stability of the dispersions was recorded by measuring the optical density of the supernatant at a fixed wavelength $(280 \mathrm{~nm})$, immediately, after 30 minutes of sonication and at defined intervals thereafter over a $28 \mathrm{~h}$ period.

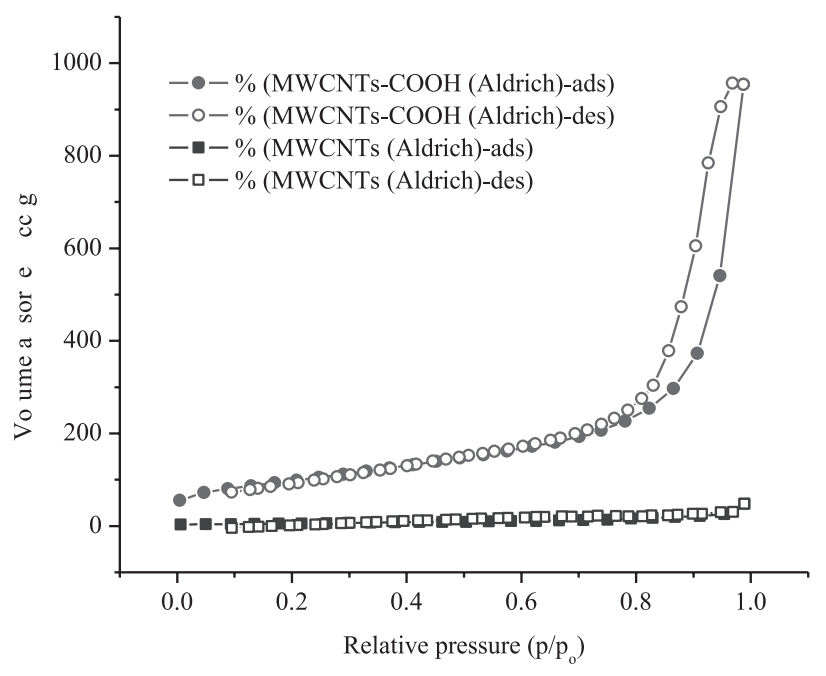

Fig. S3. $\mathrm{N}_{2}$ adsorption-desorption isotherms of pristine MWCNTs and functionalized MWCNTs- $\mathrm{COOH}$.

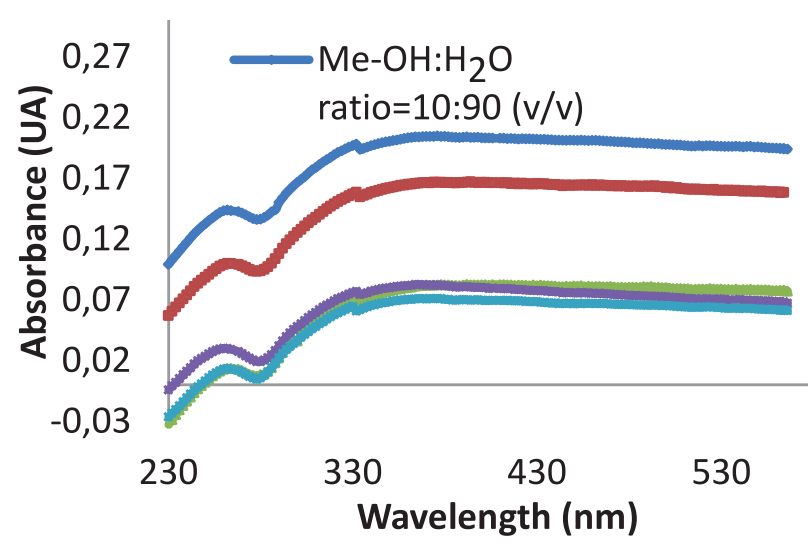

Fig. S4. UV-Vis spectra of MWCNTs dispersed in water at different methanol: water ratios MWCNTS concentration of $0.01 \mathrm{~g} / \mathrm{L}$

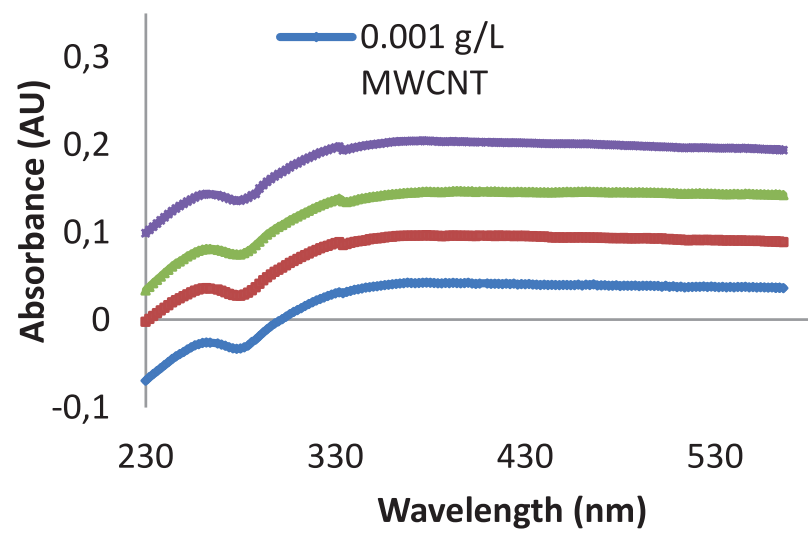

Fig. S5. UV-Vis spectra of MWCNTs dispersed in water at different concentrations for a methanol: water ratio of 10:90. 


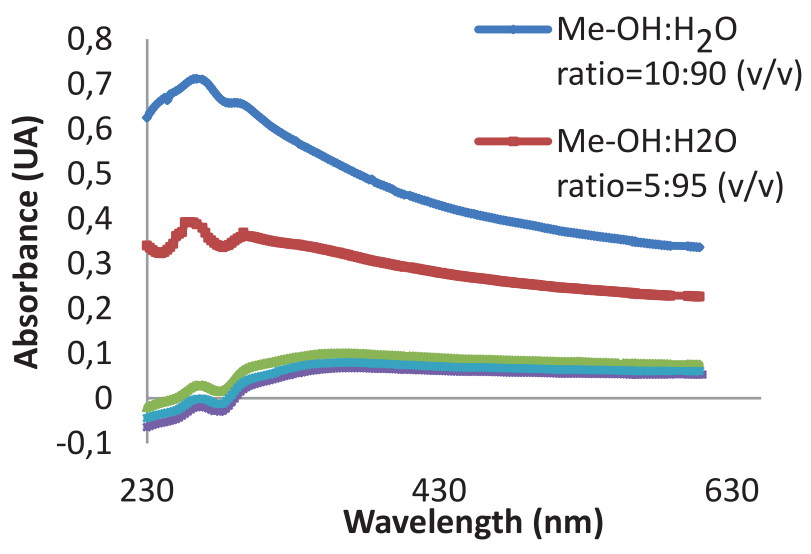

Fig.S 6 UV-Vis spectra of MWCNTs-COOH dispersed in water at different methanol: water ratios for a concentration of $0.01 \mathrm{~g} / \mathrm{L}$.

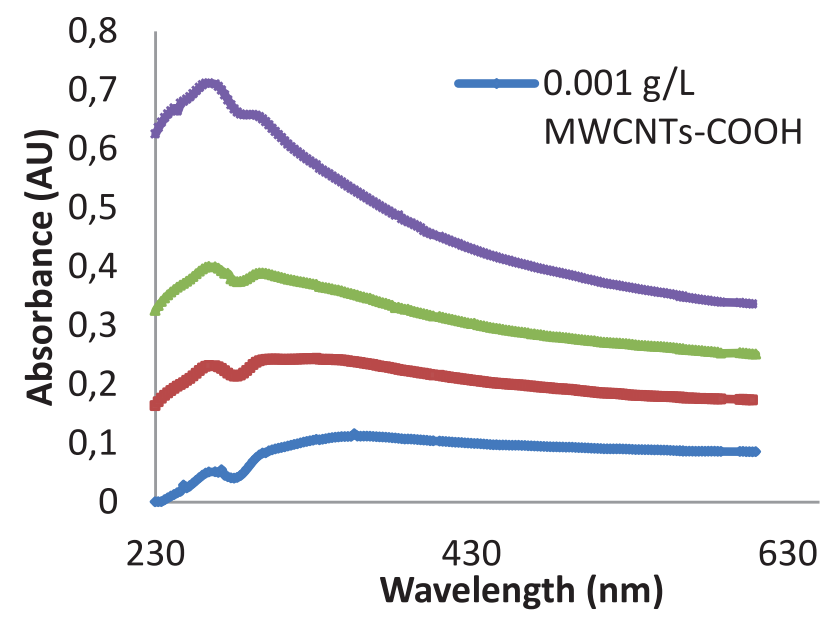

Fig. S 7 UV-Vis spectra of MWCNTs-COOH dispersed in water at different concentrations for a methanol: water ratio of 10:90

a)

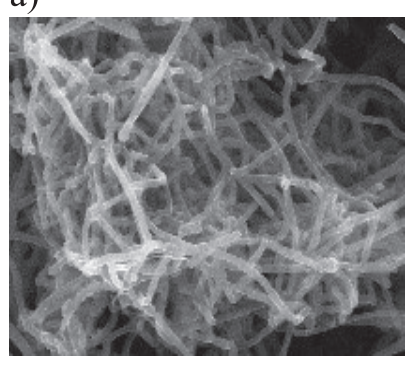

b)

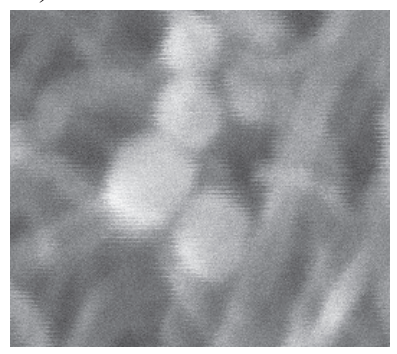

Fig. S8. SEM images of MWCNTs pristine and $-\mathrm{COOH}$ impregnated with BPA: a) BPA MWCNTs; b) BPA - MWCNTs $\mathrm{COOH}$.
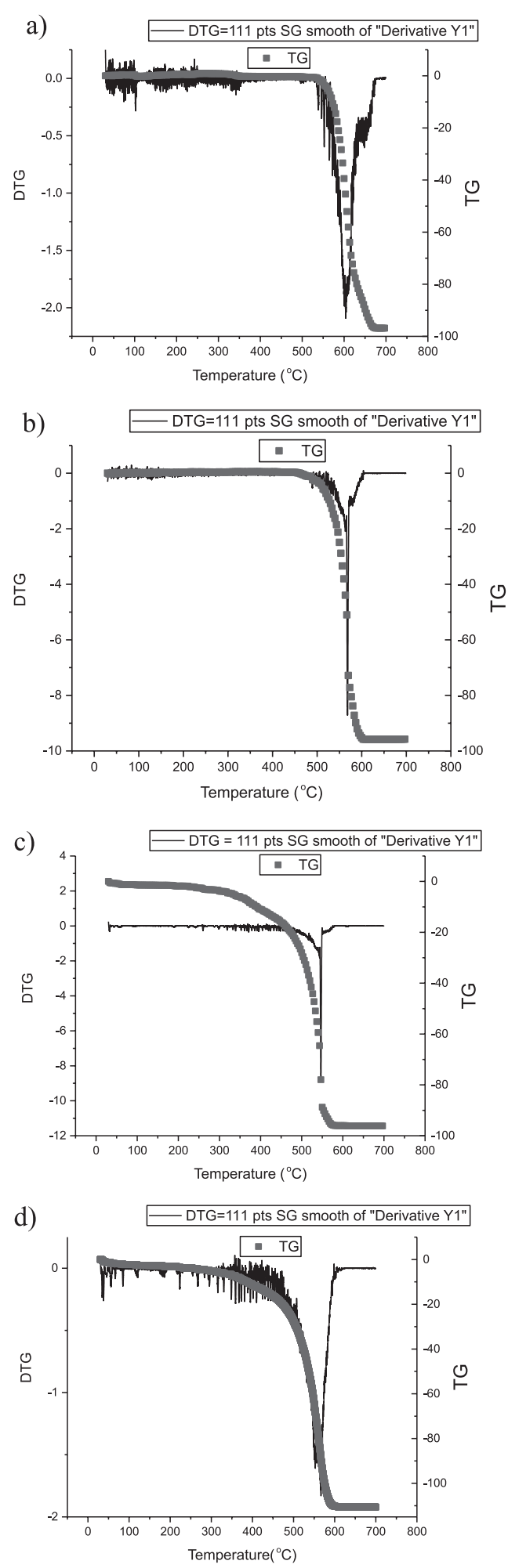

Fig. S9. TGA analysis for MWCNTs and MWCNTs $-\mathrm{COOH}$, before (b, d) and after $(a, c)$ the sorption of BPA. 
a)

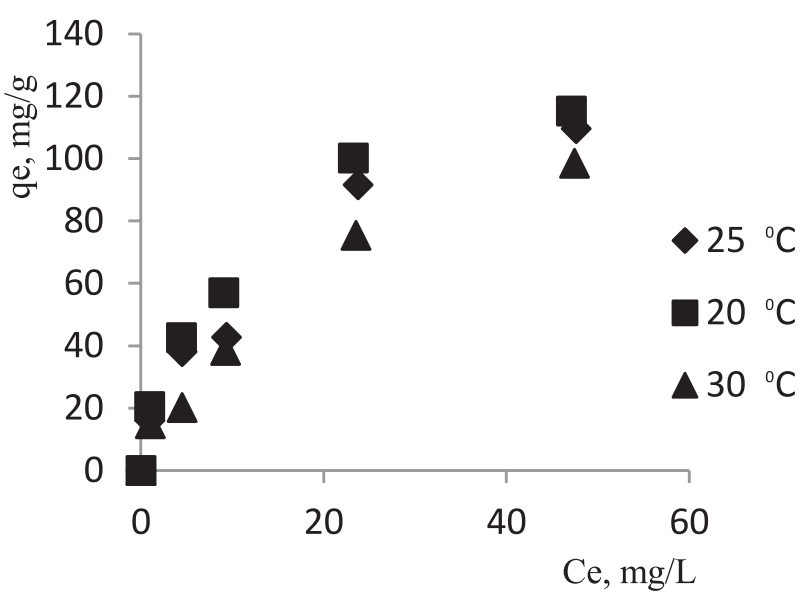

b)

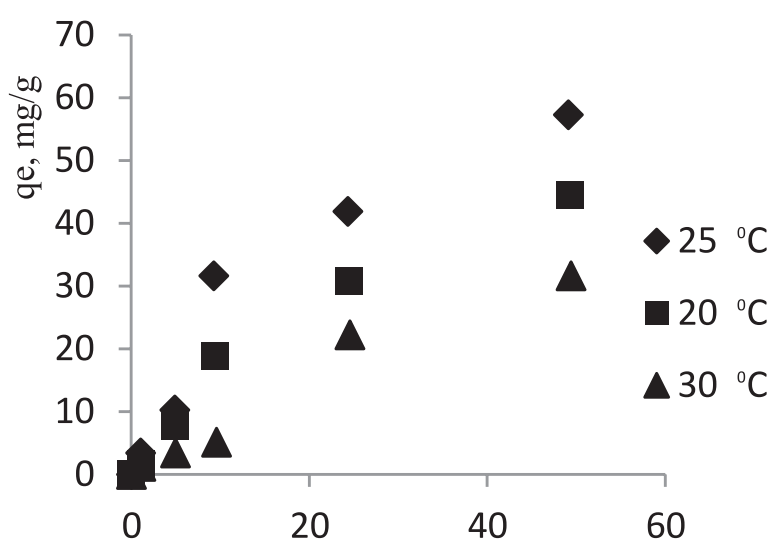

$\mathrm{Ce}, \mathrm{mg} / \mathrm{L}$

Fig. S10. Adsorption isotherms of BPA on MWCNTs a) and MWCNTs $-\mathrm{COOH}$ b); Conditions: $\mathrm{C}_{i}=1-50 \mathrm{mg} / \mathrm{L} \mathrm{BPA}, \mathrm{T}=25$, $20,35^{\circ} \mathrm{C}, \mathrm{V}=100 \mathrm{~mL}$, contact time 3 hours, equilibrium reached after 30 minutes.

\section{References}

1. ZHANG Y. On the climatic uncertainty to the environment extremes: a Singapore case and statistical approach. Polish Journal of Environmental Studies, 24, 1413, 2015.

2. MA X., AGARWAL S. Adsorption of emerging ionizable contaminants on carbon nanotubes: Advancements and Challenges. Molecules, 21, 628, 2016.

3. GU W., CHENG B., LI Y., Interference adsorption of cadmium with a variety of pollutants in sediments based on fractional factorial design (Resolution V). Polish Journal of Environmental Studies, 26 (1), 47, 2017.

4. RADU E., ION A.C., SIRBU F., ION I. Adsorption of endocrine disruptors on exfoliated graphene nanoplatelets. Environmental Engineering and Management Journal, 14 (3), 551, 2015.

5. LAZIM Z.M., HADIBARATA T., PUTEH M.H., YUSOP $Z$. Adsorption characteristics of bisphenol A onto low-cost modified phyto-waste material in aqueous solution. Water, Air\&SoilPollution, 226 (34), 1, 2015.

6. WANG W., JIANG C., ZHU L., LIANG N., LIU X., JIA J., ZHANG C., ZHAI S., ZHANG B. Adsorption of bisphenol $A$ to a carbon nanotube reduced its endocrine disrupting effect in mice male offspring. International Journal of Molecular Science, 15 (9), 15981, 2014.

7. BALARAK D. Kinetics, isotherm and thermodynamics studies on Bisphenol A adsorption using Barley husk. International Journal of ChemTech Research, 9( 5), 681, 2016.

8. AMADI M.T., SHOKOOHI R., POORMOHAMMADI A., AZARIAN G., HARATI M.,SHANESAZ A. Removal of bisphenol A using antimony nanoparticle multi-walled carbon nanotubes composite from aqueous solutions. Oriental Journal of Chemistry, 32 (2), 1015, 2016.

9. BHATNAGAR A., ANASTOPOULOI A. Adsorptive removal of bisphenol a (BPA) from aqueous solution: A review. Chemosphere, 168, 885, 2017.

10. MURUGESAN K., SALAM H.A., SIVARAJ R., VENCKATESH R. Detection of bisphenolA in various environment samples collected from Tamil Nadu, India by solid-phase extraction and GC analysis. Advances in Bioresearch, 4 (1), 59, 2013.

11. NENG N.R., NOGUEIRA J.M.F. Determination of phenol compounds in surface water matrices by bar adsorptive microextraction-high performance liquid chromatography-diode array detection. Molecules, 19, 9369, 2014.

12. MAUTER M.S., ELIMELECH M. Environmental applications of carbon-based nanomaterials. Environmental Science \& Technology, 42 (16), 5843, 2008.

13. KUO K.Y. Comparison with as-grown and microwave modified carbon nanotubes to removal aqueous bispheno 1 A. Desalination, 249, 976, 2009.

14. HEO J., FLORA J.R.V., HER N., PARK, Y.G., CHO J., SON A., YOON Y. Removal of bisphenol A and 17 $\beta$-estradiol in single walled carbon nanotubes-ultrafiltration (SWNTs -UF) membrane systems. Separation and Purification Technology, 90, 39, 2012.

15. PAN B.D., LIN H., MASHAYEKHI B., XING B. Adsorption and hysteresis of bisphenol A and $17 \alpha$-ethinyl estradiol on carbon nanomaterials. EnvironmentalScience \&Technology, 42 (15), 5480, 2008.

16. GOMA H.S., ALI, A. M., GUPTA V. K., HAMDY A. S., RAMIN M., MALLIKARJUNA S., NADAGOUDA N., SILLANPÄÄ M., MEGIEL E. The role of nanomaterials as effective adsorbents and their applications in wastewater treatment. Journal of Nanostructure in Chemistry, 7 (1), 1, 2017.

17. ASUNCIÓN M.L., MENDIETA V.S., HERNÁNDEZ A.L.M., CASTAÑO V.M., SANTOS C.V. Adsorption of phenol from aqueous solutions by carbon nanomaterials of one and two dimensions: kinetic and equilibrium studies. Journal of Nanomaterials, 16 (1), 422, 2015.

18. MARSH D.H., RANCE G.A., ZAKA M.H., WHITBY R.J., KHLOBYSTOV A.N. Comparison of the stability of multiwalled carbon nanotube dispersions in water. Physical Chemistry and Chemical Physics, 9, 5490, 2007.

19. SHI Y., REN L., LI D., GAO H., YANG B. Optimization Conditions for Single-Walled Carbon Nanotubes Dispersion. Journal of Surface Engineered Materials and Advanced Technology, 3, 6, 2013.

20. ZHAO J., WANG Z., GHOSH S., XING B. Phenanthrene binding by humic acid-protein complexes as studied by passive dosing technique. Environmental Pollution, 184, 145, 2014.

21. YANG W.B., LU Y.P., ZHENG F.F. Removal and Adsorption of p-Nitrophenol from Aqueous Solutions Using Carbon Nanotubes and Their Composites. Chemical Engineering Journal, 179, 112, 2012. 
22. LIU X, WANG X.C., TAN F. Developments and Trends of Molecularly Imprinted Solid-Phase Microextraction. Analytica Chimica Acta, 727, 26, 2012.

23. APUL O.G., WANG Q., ZHOU Y., KARANFIL T. Adsorption of aromatic organic contaminants by Graphene nanosheets: comparison with carbón nanotubes and activated carbon. Water Resources, 47, 1648, 2013.

24. WU W., YANG K., CHEN W., ZHANG J., LIN D., XING B. Correlation and prediction of adsorption capacity and affinity of aromatic compounds on carbón nanotubes. Water Research, 88, 492, 2016.
25. LIBBRECHT W., VANDAELE K., BUYSSER K., VERBERCKMOES A., THYBAUT J.W., POELMAN H., CLERCQ VAN DER VOORT J.P. Tuning the Pore Geometry of Ordered Mesoporous Carbons for Enhanced Adsorption of Bisphenol-A. Materials, 8, 1652, 2015.

26. PHATTHANAKITIPHONG T., SEO G.T. Characteristic Evaluation of Graphene Oxide for Bisphenol A Adsorption in Aqueous Solution. Nanomaterials, 6, 128, 2016.

27. XU J., ZHU Y. F. Elimination of Bisphenol A from Water via Graphene Oxide Adsorption. Acta PhysicoChimicaSinica, 29, 829, 2013. 